\title{
A preliminary study of the incorparation of NPK fertilizer into chitosan nanoparticles
}

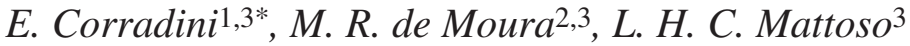 \\ ${ }^{1}$ Depto. de Engenharia de Materiais da UFSCar, CP 676, 13560-905 São Carlos, SP, Brazil \\ 2IFSC, Universidade de São Paulo, CP 369, 13560-970, São Carlos SP, Brazil \\ ${ }^{3}$ Laboratório Nacional de Nanotecnologia para o Agronegócio Embrapa/CNPDIA, CP 741, 13560-970, São Carlos, SP, \\ Brazil
}

Received 10 February 2010; accepted in revised form 30 April 2010

\begin{abstract}
The use of slow release fertilizer has become a new trend to save fertilizer consumption and to minimize environmental pollution. Due to its polymeric cationic, biodegradable, bioabsorbable, and bactericidal characteristics, chitosan (CS) nanoparticle is an interesting material for use in controlled release systems. However, there are no attempts to explore the potential of chitosan nanoparticles as controlled release for NPK fertilizers. In this work chitosan nanoparticles were obtained by polymerizing methacrylic acid for the incorporation of NPK fertilizers. The interaction and stability of chitosan nanoparticle suspensions containing nitrogen $(\mathrm{N})$, phosphorus $(\mathrm{P})$ and potassium $(\mathrm{K})$ were evaluated by FTIR spectroscopy, particle size analysis and zeta-potential. The FTIR results indicated the existence of electrostatic interactions between chitosan nanoparticles and the elements N, P and K. The stability of the CS-PMAA colloidal suspension was higher with the addition of nitrogen and potassium than with the addition of phosphorus, due to the higher anion charge from the calcium phosphate than the anion charges from the potassium chloride and urea. The mean diameter increase of the CS-PMAA nanoparticles in suspension with the addition of different compounds indicated that the elements are being aggregated on the surface of the chitosan nanoparticles.
\end{abstract}

Keywords: nanomaterials, chitosan, NPK fertilizers, zeta potential

\section{Introduction}

Fertilizers are chemical compounds applied to promote plant and fruit growth [1]. Fertilizers are usually applied either through the soil (for uptake by plant roots) or by foliar feeding (for uptake through leaves). Fertilizers can also be applied to aquatic environments, notably ocean fertilization. Artificial fertilizers are inorganic fertilizers formulated in appropriate concentrations and the combinations supply three main nutrients: nitrogen, phosphorus and potassium ( $\mathrm{N}, \mathrm{P}$ and $\mathrm{K}$ ) for various crops and growing conditions. $\mathrm{N}$ (nitrogen) promotes leaf growth and forms proteins and chlorophyll. $\mathrm{P}$ (phosphorus) contributes to root, flower and fruit devel- opment. K (potassium) contributes to stem and root growth and the synthesis of proteins $[2,3]$.

However, about $40-70 \%$ of nitrogen, $80-90 \%$ of phosphorus, and $50-70 \%$ of potassium of the applied normal fertilizers is lost to the environment and cannot be absorbed by plants, causing not only substantial economic and resource losses but also very serious environmental pollution $[4,5]$. Recently, the use of slow release fertilizers has become a new trend to save fertilizer consumption and to minimize environmental pollution $[6,7]$. This brings out the idea of developing encapsulated fertilizers, in which NPK fertilizers are entrapped within nanoparticles [8]. Consequently, the fertiliz- 
ers are protected by the nanoparticles for better survival in inoculated soils, allowing for their controlled release into the soil [5]. Therefore, the method of encapsulation of fertilizers components in polymeric nanoparticles is relatively novel, with potential commercial applications.

Chitosan nanoparticles have been investigated as a carrier for drug delivery, although have been no attempts to explore the potential of chitosan nanoparticles as controlled release for NPK fertilizers. Chitosan (CS) is a polymer of particular interest in this area because it is biodegradable, bioabsorbable, and bactericidal $[9,10]$. Due to its polymeric cationic characteristics, chitosan nanoparticles may interact with negatively charged molecules and polymers, showing a favorable interaction. The ability of controlling nanoparticle size is highly desirable for most applications in the field of nanotechnology [11].

In this work chitosan nanoparticles were obtained by polymerizing methacrylic acid for the incorporation of NPK fertilizers. The interaction and stability of chitosan nanoparticle suspensions containing $\mathrm{N}, \mathrm{P}$ and $\mathrm{K}$ were evaluated by FTIR spectroscopy, particle size analysis and zeta-potential.

\section{Experimental}

\subsection{Materials}

Chitosan (CS) (MW $71.3 \mathrm{kDa}$, degree of deacetylation 94\%) was purchased from Polymar Ciência e Nutrição S/A (Fortaleza, Brazil).

All reagents were of analytical grade. Potassium persulfate $\left(\mathrm{K}_{2} \mathrm{~S}_{2} \mathrm{O}_{8}\right)$ and methacrylic acid (MAA) were purchased from Sigma-Aldrich Química Brasil Ltda (São Paulo, Brazil). Calcium phosphate $\mathrm{Ca}\left(\mathrm{H}_{2} \mathrm{PO}_{4}\right)_{2} \cdot \mathrm{H}_{2} \mathrm{O}$, urea $\mathrm{CO}\left(\mathrm{NH}_{2}\right)_{2}$ and potassium chloride $\mathrm{KCl}$ were purchased from Synth-Labsynth Produtos para laboratórios Ltda (Diadema, SP, Brazil).

\subsection{Preparation of CS-PMAA nanoparticles}

The CS-PMAA nanoparticles were obtained by polymerization of MAA in CS solution in a twostep process [11]. In the first step, chitosan was dissolved in a $0.5 \%(\mathrm{v} / \mathrm{v})$ methacrylic acid aqueous solution for $12 \mathrm{~h}$ under magnetic stirring. The CS concentration used in synthesis was $0.2 \%(\mathrm{w} / \mathrm{v})$. In the second step, $0.2 \mathrm{mmol}$ of $\mathrm{K}_{2} \mathrm{~S}_{2} \mathrm{O}_{8}$ was added to the solution with continued stirring, until the solution became clear. The polymerization was then carried out at $70^{\circ} \mathrm{C}$ under magnetic stirring for $1 \mathrm{~h}$ leading to the formation of CS-PMAA nanoparticles, which was then cooled in an ice bath.

\subsection{Characterization of CS-PMAA nanoparticles}

The zeta potential measurements and particle size distribution of CS nanoparticules were taken on a Zetasizer NanoZS (Malvern Instruments, Worcestershire, UK). The measurements were carried out after equilibrating the prepared samples at several $\mathrm{pH}$ values $(2.0-12.0)$ at $25^{\circ} \mathrm{C}$. All analyses were performed in triplicate.

The morphology and size of the CS-PMAA nanoparticles were investigated using a Philips CM200 transmission electron microscope (Philips Electronic Instruments, Mahwah, NJ, USA). CS-PMAA nanoparticle emulsions were sonicated for $2 \mathrm{~min}$ to produce better particle dispersion and to prevent the nanoparticle agglomeration on the copper grid. One drop of the nanoparticle emulsion was spread onto a carbon-coated copper grid and was then dried at room temperature for transmission electron microscopy (TEM) analysis. The sizes of the nanoparticles were determined directly from the figure using an Image-Pro Plus 4.5 software. The value is an average size of five parallels.

\subsection{Incorporation of NPK fertilizer in chitosan nanoparticles}

There are many types of commercial fertilizers that consist of mixing the substances containing nitrogen $(\mathrm{N})$, phosphorus $(\mathrm{P})$ and potassium $(\mathrm{K})$ in different proportions. In this study, the sources of N, P and $\mathrm{K}$ used were urea, calcium phosphate, and potassium chloride, respectively. These substances were used separately.

The incorporation of NPK fertilizers in chitosan nanoparticles was obtained by dissolving different amounts of NPK into $50 \mathrm{ml}$ of nanoparticle solution under magnetic stirring for $6 \mathrm{~h}$ at $25^{\circ} \mathrm{C}$. The resulting solution to incorporate NPK into the nanoparticles presents this final concentration: i) $20,40,60,80,100,200,300,400$ and $500 \mathrm{ppm}$ of $\mathrm{N}$; ii) $10,20,30,40,50$ and $60 \mathrm{ppm}$ of P; iii) 20 , $40,60,80,100,200,300$ and $400 \mathrm{ppm}$ of $\mathrm{K}$. The 
maximum $\mathrm{P}$ solution concentration was of $60 \mathrm{ppm}$ because the solution will precipitate at higher concentrations. The resulting solutions had a $\mathrm{pH}$ between 4.2 and 4.7

\subsection{Characterization of the nanoparticles with NPK fertilizers}

The zeta potential and particle size distribution measurements of CS-PMAA suspension nanoparticles with entrapment of NPK fertilizers in different concentrations were carried out in a Zetasizer NanoZS (Malvern Instruments, Worcestershire, $\mathrm{UK})$ at $\mathrm{pH}$ of the resulting solutions and at $25^{\circ} \mathrm{C}$.

\subsection{FT-IR analysis}

CS-PMAA nanoparticle suspensions with 500, 60 and $500 \mathrm{ppm}$ of $\mathrm{N}, \mathrm{P}$ and $\mathrm{K}$, respectively were prepared as described in chapter 2.4. The nanoparticle suspensions with/without entrapment of NPK fertilizers were frozen by liquid nitrogen and lyophilized by a freeze drying system in order to obtain dried nanoparticles. FT-IR spectra were taken on a Perkin Elmer Spectrum model Paragon 1000 (Perkin-Elmer Life and Analytical Sciences, Inc., Waltham, MA USA), in the range of 4000 to $400 \mathrm{~cm}^{-1}$ to evaluate the chemical interaction between NPK fertilizers and CS nanoparticles. Powdered samples were prepared using $\mathrm{KBr}$ to form pellets.

\section{Results and discussion}

During the synthesis of chitosan nanoparticles, it was observed that the chitosan solution in methacrylic acid (MAA) changed from a clear to an opalescent suspension. This transformation is an evidence of the formation of chitosan nanoparticles with MAA. According to the mechanism proposed by Vasconcelos et al. [12], the formation of nanoparticles occurs via inter and intra-molecular linkages between PMAA carboxyl groups and amino groups of chitosan during the polimerization of MAA.

Figure 1 shows a transmission electron microscopy (TEM) image of the chitosan nanoparticles (CS-PMAA). The nanoparticles showed a spherical shape with a homogeneous size distribution. The mean diameter of the chitosan nanoparticles (in the dry state) was of approximately $78 \pm 1.5 \mathrm{~nm}$, which

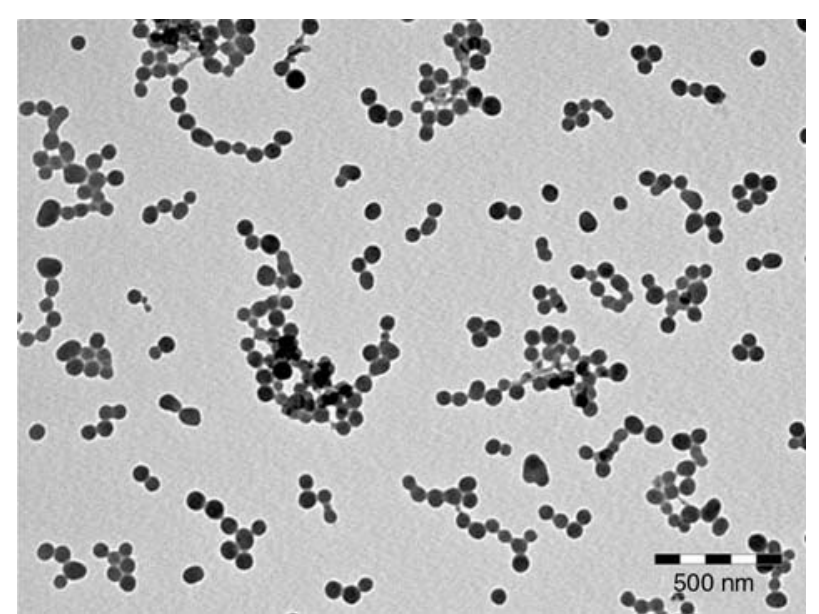

Figure 1. TEM microphotograph obtained for chitosan nanoparticles (CS-PMAA) at $\mathrm{pH} 4$

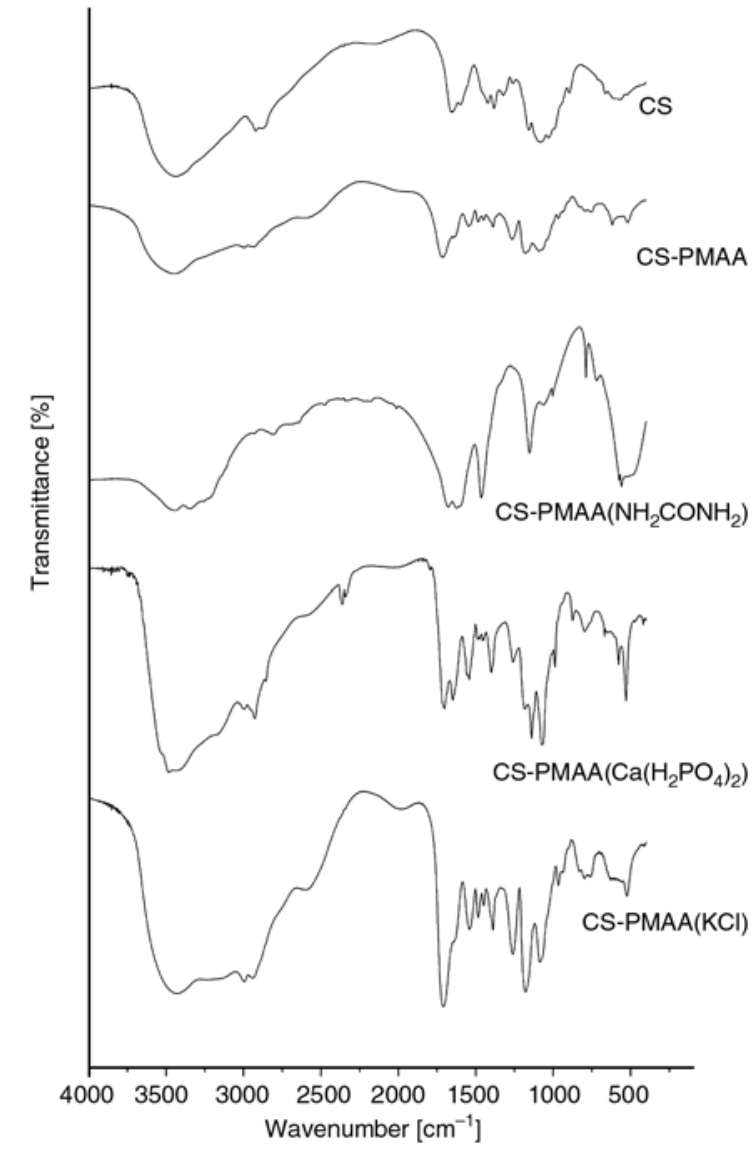

Figure 2. FT-IR transmitance spectra of raw chitosan (CS), chitosan nanopaticles (CS-PMAA) and nanoparticles with urea (CS-PMAA $\left.\left(\mathrm{NH}_{2} \mathrm{CONH}_{2}\right)\right)$, with calcium phosphate $\left(\left(\mathrm{CS}-\mathrm{PMAA}\left(\mathrm{Ca}\left(\mathrm{H}_{2} \mathrm{PO}_{4}\right)_{2} \cdot \mathrm{H}_{2} \mathrm{O}\right)\right)\right.$, and potassium chloride (CS-PMAA $(\mathrm{KCl})$ )

is higher in suspension due to the nanoparticles' swelling ability.

Figure 2 shows the FTIR spectra of pure chitosan (CS), of the CS-PMAA nanoparticles and of the nanoparticles loaded with urea (CS-PMAA 
$\left(\mathrm{NH}_{2} \mathrm{CONH}_{2}\right)$ ), calcium phosphate (CS-PMAA $\left.\left(\mathrm{Ca}\left(\mathrm{H}_{2} \mathrm{PO}_{4}\right)_{2} \cdot \mathrm{H}_{2} \mathrm{O}\right)\right)$ and potassium chloride $(\mathrm{CS}-$ PMAA $(\mathrm{KCl})$ ). The FTIR spectrum obtained for the chitosan (CS) has characteristic peaks: $3435 \mathrm{~cm}^{-1}$ corresponding to the stretching of the $\mathrm{NH}_{2}$ and $\mathrm{OH}$ groups; $1649 \mathrm{~cm}^{-1}$ corresponding to the $\mathrm{C}=\mathrm{O}$ group of amide I; $1083-1020 \mathrm{~cm}^{-1}$ due to the stretching of $\mathrm{C}-\mathrm{O}$ and $620 \mathrm{~cm}^{-1}$, due to vibrations of the pyranosidic rings [13]. It is observed that the band at $1649 \mathrm{~cm}^{-1}$, characteristic of pure chitosan, disappears in the spectrum of the nanoparticles and two new bands appear at $1638 \mathrm{~cm}^{-1}$ (group $-\mathrm{COO}^{-}$) and $1545 \mathrm{~cm}^{-1}$ (group $-\mathrm{NH}_{3}{ }^{+}$), indicating the interaction between PMAA and CS. The bands at 1703 and $1264 \mathrm{~cm}^{-1}(\mathrm{C}=\mathrm{O})$ show the presence of PMAA in the nanoparticles [14].

Comparing the spectrum obtained for CS-PMAA with those obtained for the loaded nanoparticles (CS-PMAA $\left(\mathrm{NH}_{2} \mathrm{CONH}_{2}\right)$ ),

(CS-PMAA $\left(\mathrm{Ca}\left(\mathrm{H}_{2} \mathrm{PO}_{4}\right)_{2} \cdot \mathrm{H}_{2} \mathrm{O}\right)$, (CS-PMAA $\left.(\mathrm{KCl})\right)$, significant differences can be observed. However, the specific peak of the CS-PMAA nanoparticle appears in the spectra of loaded nanoparticles, hence suggesting that there was no change in the structure of the nanoparticles with the incorporation of $\mathrm{N}, \mathrm{P}$ and $\mathrm{K}$ fertilizers. The main changes observed in the spectrum of the nanoparticles loaded with urea (CS-PMAA $\left(\mathrm{NH}_{2} \mathrm{CONH}_{2}\right)$ ), when compared to the spectrum of CS-PMAA, occurred at $1400-1500 \mathrm{~cm}^{-1}$ region. A strong peak is observed at $1400 \mathrm{~cm}^{-1}$ due to deformation of ammonium ions $\left(-\mathrm{NH}_{4}{ }^{+}\right)$, which usually occurs at ca. $1500 \mathrm{~cm}^{-1}$ [15]. This shifting between the two peaks suggests some interaction between $-\mathrm{NH}_{4}{ }^{+}$ groups of urea and $-\mathrm{COO}^{-}$groups of CS-PMMA nanoparticles. For the nanoparticles loaded with calcium phosphate $\left(\mathrm{CS}-\mathrm{PMAACa}\left(\mathrm{H}_{2} \mathrm{PO}_{4}\right)_{2} \cdot \mathrm{H}_{2} \mathrm{O}\right)$, the main change in the FTIR spectrum regarding the spectrum of the CS-PMAA nanoparticles, is the increase in the absorption intensity at $1547 \mathrm{~cm}^{-1}$, indicating the interaction between the $-\mathrm{NH}_{3}{ }^{+}$group of the chitosan nanoparticles and the $\mathrm{P}_{2} \mathrm{PO}_{4}{ }^{-}$and $\mathrm{PO}_{4}{ }^{2-}$ groups of calcium phosphate. The appearance of two intense bands was also noted at about 530 and $1070 \mathrm{~cm}^{-1}$, corresponding to the calcium phosphate grouping $[16,17]$ that was incorporated into the chitosan nanoparticles. The main change observed in the spectrum of the nanoparticles loaded with $\mathrm{KCl}$ occurred at about $1460 \mathrm{~cm}^{-1}$, which is probably due to the interaction of the $-\mathrm{COO}^{-}$groups of chitosan nanoparticles with the potassium chloride $\mathrm{K}^{+}$groups.

Figure 3 illustrates the zeta potential as a function of the $\mathrm{pH}$ for the CS-PMAA nanoparticles. The variation of the zeta potential with the $\mathrm{pH}$ values is a consequence of the loading density changes on the nanoparticles' surface. The positive values of the zeta potential indicate that the CS-PMAA nanoparticles are positively loaded due to the cationic characteristics of chitosan in the $\mathrm{pH}$ range of 2 to 5.5. The isoelectric point of the system is at $\mathrm{pH}=5.5$, where the positive and negative charges are equal. It is an indication that at this $\mathrm{pH}$ the system has certain instability. At a pH greater than 5.5 negative zeta potential values are observed, indicating that the surface of the nanoparticles are negatively charged due to ionization of the carboxyl groups of PMAA and the neutralization of the $-\mathrm{NH}_{2}$ groups of $\mathrm{CS}$.

The stability of a colloidal dispersion is a consequence of the electrical double layer on the surface of the colloidal particles. The addition of an electrolyte to a colloidal dispersion suppresses the diffuse double layer and reduces the zeta potential. This drastically reduces the electrostatic repulsion between the particles and precipitates the colloid. The colloid is extremely sensitive to ions of opposite sign. A positively charged colloidal dispersion is precipitated by negative ions, these ions are incorporated into the fixed portion of the double layer, reducing the total charge of the particle. Similarly, a negatively charged colloidal dispersion will be destabilized by positive ions. The ion with

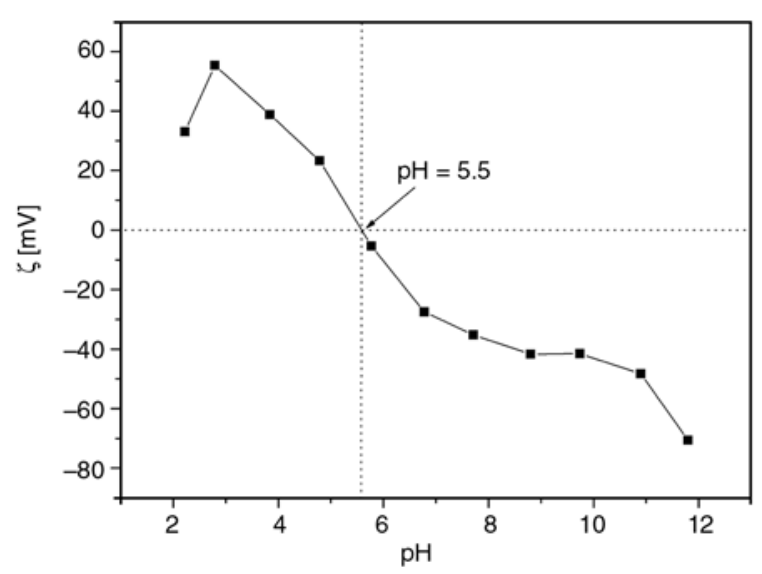

Figure 3. Dependence of zeta potential $(\zeta)$ on $\mathrm{pH}$ for chitosan nanoparticles (CS-PMAA) 
the same charge of the colloidal particle has little effect on precipitation [18].

NPK fertilizer components (urea, calcium phosphate and potassium chloride) that were added to the CS-PMAA suspensions dissociate in aqueous acid solutions according to the reactions (1)-(3) below:

$$
\begin{aligned}
& \mathrm{CO}\left(\mathrm{NH}_{2}\right)_{2(s)}+2 \mathrm{H}_{(a q)}^{+}+2 \mathrm{H}_{2} \mathrm{O}_{(l)} \\
& \Leftrightarrow 2 \mathrm{NH}_{4(a q)}^{+}+\mathrm{H}_{2} \mathrm{CO}_{3(a q)} \\
& \mathrm{KCl}_{(s)} \Leftrightarrow \mathrm{K}_{(a q)}^{+}+\mathrm{Cl}_{(a q)}^{-} \\
& \mathrm{Ca}\left(\mathrm{H}_{2} \mathrm{PO}_{4}\right)_{2} \cdot \mathrm{H}_{2} \mathrm{O}_{(s)} \Leftrightarrow \mathrm{Ca}_{(a q)}^{+2}+\mathrm{H}_{2} \mathrm{PO}_{4(a q)}^{-}+\mathrm{H}_{2} \mathrm{O}_{(l)} \\
& \mathrm{H}_{2} \mathrm{PO}_{4(a q)}^{-} \Leftrightarrow \mathrm{HPO}_{4(a q)}^{-2}+\mathrm{H}_{(a q)}^{+}
\end{aligned}
$$

The stability of colloidal suspension of the CS-PMAA nanoparticles at $\mathrm{pH}$ values lower than 5.5 is influenced by the presence of positive ions, since the colloidal suspension of CS-PMAA is positively charged. The precipitation of the colloidal suspension of CS-PMAA was observed with the addition of amounts greater than $400 \mathrm{ppm}$ of $\mathrm{N}$ and $\mathrm{K}$ and amounts greater than $60 \mathrm{ppm}$ of $\mathrm{P}$. This difference is probably related to the greater charge of the anion $\mathrm{H}_{2} \mathrm{PO}_{4}{ }^{2-}$ (from the electrolyte $\mathrm{Ca}\left(\mathrm{H}_{2} \mathrm{PO}_{4}\right)_{2} \cdot \mathrm{H}_{2} \mathrm{O}$ ) compared to the anion $\mathrm{Cl}^{-}$(from the electrolyte $\mathrm{KCl}$ ), because the higher the ion charge, the higher the precipitation efficiency of the colloid.

Figures $4 \mathrm{a}, 4 \mathrm{~b}$ and $4 \mathrm{c}$ show the zeta potential values and mean particle diameter due to the quantity of phosphorus, nitrogen and potassium, respectively (after 6 hours of mechanical agitation). The mean diameter of the CS-PMAA nanoparticles in suspension was of approximately $142 \mathrm{~nm}$ and increased with the addition of the different compounds. The maximum increase in the mean diameter was of $53 \%$ with the addition of $60 \mathrm{ppm}$ of phosphorus, of $32 \%$ with $400 \mathrm{ppm}$ of nitrogen and of $13 \%$ with the addition of $400 \mathrm{ppm}$ of potassium. These values are probably related to the size of the species separated in the colloidal suspension, and the separated species from the $\mathrm{KCl}$ have a smaller volume than the separated species from the urea and calcium phosphate. It was found that for the colloidal dispersions of CS-PMAA with phosphorus, the zeta potential values $(\zeta)$ were not significantly altered with the addition of up to $60 \mathrm{ppm}$ of phos-
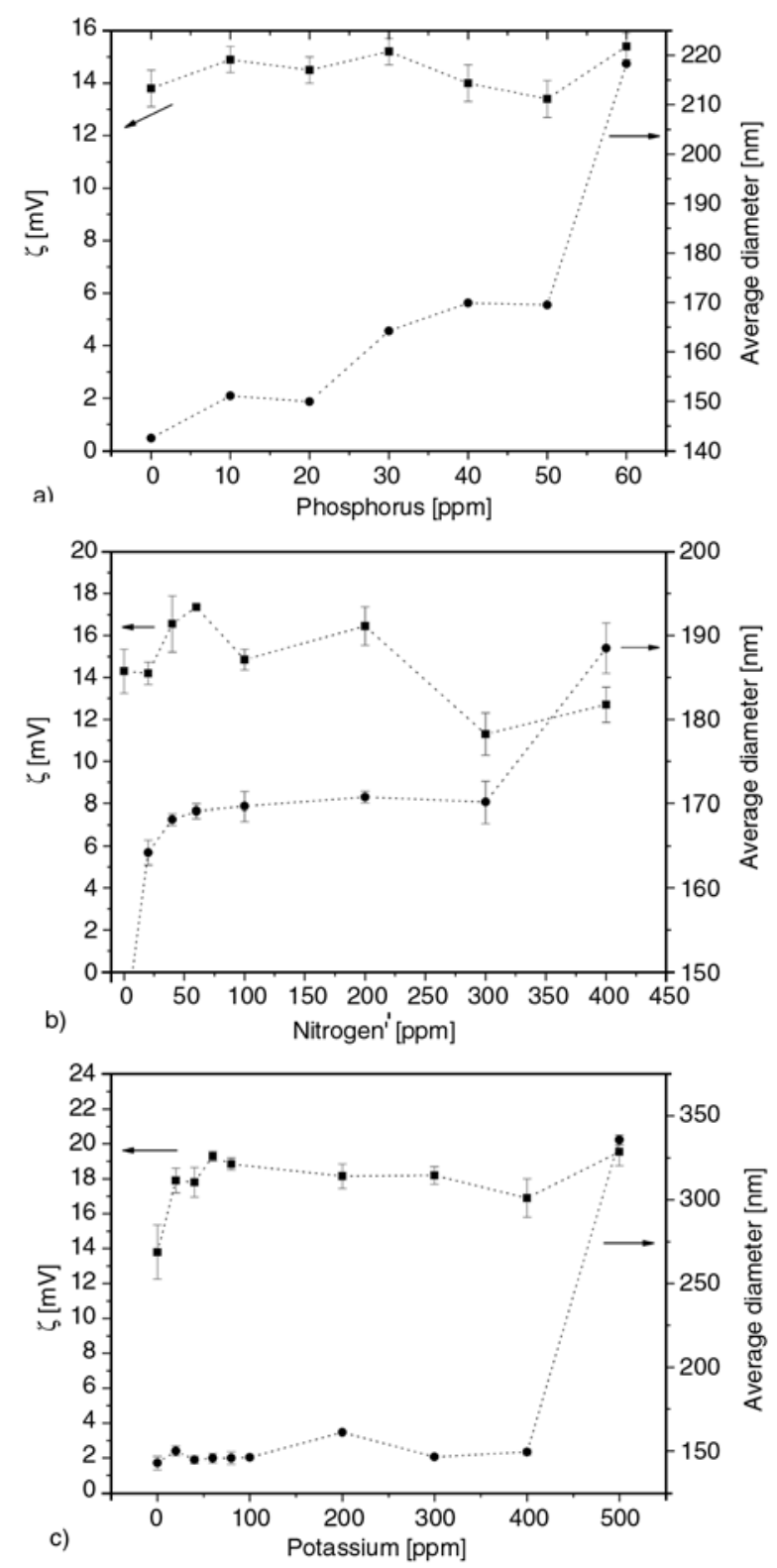

Figure 4. Zeta potencial $(\zeta)$ and average diameter [nm] for dispersion of chitosan (CS-PMAA) as a function of the amount of phosphorus (a), nitrogen (b) and potassium (c)

phorus, indicating the stability of the colloidal system under the conditions studied.

The $\zeta$ values of the dispersions of CS-PMAA loaded with up to $200 \mathrm{ppm}$ of $\mathrm{N}$ were higher when compared to the $\zeta$ value of the dispersion of pure CS-PMAA and for the dispersions with higher amounts of $\mathrm{N}$ to $200 \mathrm{ppm}$, the values of $\zeta$ were lower. This indicates that above $200 \mathrm{ppm}$ a suppression of positive charges is occurring in the colloidal dispersion of CS-PMAA, which must be due to the presence of negative groups from the urea molecules $\left(\mathrm{NH}_{2} \mathrm{CONH}_{2}\right)$. For dispersions with potassium, the zeta potential showed an increase 
with the addition of potassium of 20 to $80 \mathrm{ppm}$ with respect to the dispersion of pure CS-PMAA, indicating an increase of positive charges in the colloidal dispersion and remaining almost constant with the addition of up to $400 \mathrm{ppm}$. This shows that the presence of the $\mathrm{Cl}^{-}$ions (from $\mathrm{KCl}$ ) did not affect the stability of colloidal dispersion with additions of up to $400 \mathrm{ppm}$ and above this amount a decrease of positive charges occurred and consequently, the precipitation of the colloidal system.

\section{Conclusions}

The chitosan nanoparticles obtained showed spherical shapes and uniform sizes of approximately $78 \mathrm{~nm}$ in the TEM micrographs. The stability of the CS-PMAA colloidal suspension was influenced by the presence of the separated species from the urea, potassium chloride and calcium phosphate. The FTIR results indicated the existence of electrostatic interactions between $-\mathrm{COO}^{-}$and $-\mathrm{NH}_{3}{ }^{+}$of the chitosan nanoparticles and the elements $\mathrm{N}, \mathrm{P}$ and $\mathrm{K}$ present in the urea, calcium phosphate, potassium chloride, respectively. The stability of the CSPMAA colloidal suspension was higher with the addition of nitrogen and potassium than with the addition of phosphorus, due to the higher anion charge from the calcium phosphate than the anion charges from the potassium chloride and urea. The mean diameter increase of the CS-PMAA nanoparticles in suspension with the addition of different compounds indicated that the elements are being aggregated on the surface of the chitosan nanoparticles. Further studies are needed to understand the mechanism and to optimize the incorporation of the $\mathrm{N}, \mathrm{P}$ and $\mathrm{K}$ elements into the CS-PMAA nanoparticles.

\section{Acknowledgements}

The authors wish to thank the financial and technical support provided by CNPq, FINEP, FAPESP.

\section{References}

[1] Behera S. K., Panda R. K.: Integrated management of irrigation water and fertilizers for wheat crop using field experiments and simulation modeling. Agricultural Water Management, 96, 1532-1540 (2009).

DOI: $\underline{\text { 10.1016/j.agwat.2009.06.016 }}$
[2] Mandal K. G., Hati K. M., Misra A. K.: Biomass yield and energy analysis of soybean production in relation to fertilizer-NPK and organic manure. Biomass and Bioenergy, 33, 1670-1679 (2009).

DOI: $10.1016 /$ j.biombioe.2009.08.010

[3] Gu Y. F., Zhang Z. P., Tu S. H., Lindström K.: Soil microbial biomass, crop yields, and bacterial community structure as affected by long-term fertilizer treatments under wheat-rice cropping. European Journal of Soil Biology, 45, 239-246 (2009).

DOI: $\underline{10.1016 / j . e j s o b i .2009 .02 .005}$

[4] Trenkel M. E.: Controlled-release and stabilized fertilizers in agriculture. International Fertilizer Industry Association, Paris (1997).

[5] Saigusa M.: Broadcast application versus band application of polyolefin-coated fertilizer on green peppers grown on andisol. Journal of Plant Nutrition, 23, 1485-1493 (2000). DOI: $10.1080 / 01904160009382116$

[6] Wu L., Liu M.: Preparation and properties of chitosancoated NPK compound fertilizer with controlledrelease and water-retention. Carbohydrate Polymers, 72, 240-247 (2008). DOI: 10.1016/j.carbpol.2007.08.020

[7] Guo M. Y., Liu M. Z., Zhan F. L., Wu L.: Preparation and properties of a slow-release membrane-encapsulated urea fertilizer with superabsorbent and moisture preservation. Industrial and Engineering Chemistry Research, 44, 4206-4211 (2005). DOI: $10.1021 / \mathrm{ie} 0489406$

[8] Teodorescu M., Lungu A., Stanescu P. O., Neamtu C.: Preparation and properties of novel slow-release NPK agrochemical formulations based on poly(acrylic acid) hydrogels and liquid fertilizer. Industrial and Engineering Chemistry Research, 48, 6527-6534 (2009). DOI: $\underline{10.1021 / i e 900254 b}$

[9] Coma V., Martial-Gros A., Garreau S., Copinet A., Salin F., Deschamps A.: Edible antimicrobial films based on chitosan matrix. Journal of Food Science, 67, 1162-1169 (2002). DOI: $10.1111 / \mathrm{j} .1365-2621.2002 . t b 09470 . \mathrm{x}$

[10] No H. K., Meyers S. P., Prinyawiwatkul W., Xu Z.: Applications of chitosan for improvement of quality and shelf life of foods: A review. Journal of Food Science, 72, 87-100 (2007). DOI: $10.1111 / \mathrm{j} .1750-3841.2007 .00383 . \mathrm{x}$

[11] de Moura M. R., Aouada F. A., Mattoso L. H. C.: Preparation of chitosan nanoparticles using methacrylic acid. Journal of Colloid and Interface Science, 321, 477-483 (2008). DOI: $10.1016 /$ j.jcis.2008.02.006

[12] de Vasconcelos C. L., Bezerril P. M., dos Santos D. E. S., Dantas T. N. C., Pereira M. R., Fonseca J. L. C.: Effect of molecular weight and ionic strength on the formation of polyelectrolyte complexes based on poly(methacrylic acid) and chitosan. Biomacromolecules, 7, 1245-1252 (2006). DOI: $10.1021 / \mathrm{bm} 050963 \mathrm{w}$ 
[13] Tonhi E., Plepis A. M. G.: Preparation and characterization of collagen-chitosan blends (in Portuguese). Química Nova, 25, 943-948 (2002).

DOI: $10.1590 /$ S0100-40422002000600011

[14] Azhgozhinova G. S., Güven O., Pekel N., Dubolazov A. V., Mun G. A., Nurkeeva Z. S.: Complex formation of linear poly(methacrylic acid) with uranyl ions in aqueous solutions. Journal of Colloid and Interface Science, 278, 155-159 (2004).

DOI: $10.1016 /$ j.jcis.2004.05.010

[15] Sterne E. J., Reynolds Jr. R. C., Zantop H.: Natural ammonium illites from black shales hosting a stratiform base metal deposit, Delong Montains, Northern Alaska. Clays and Clay Minerals, 30, 161-166 (1982).
[16] Nordström E. G., Karlsson K. H.: Carbonate-doped hydroxyapatite. Journal of Materials Science: Materials in Medicine, 1, 182-184 (1990).

DOI: $10.1007 / \mathrm{BF} 00700880$

[17] Kandori K., Yasukawa A., Ishikawa T.: Preparation and characterization of spherical calcium hydroxyapatite. Chemistry of Materials, 7, 26-32 (1995). DOI: $10.1021 / \mathrm{cm} 00049 \mathrm{a} 007$

[18] Castellan G.: Fundamentals of physical-chemistry (in Portuguese). Livros Técnicos e Científicos Editora, Rio de Janeiro (1995). 